\title{
Comparative genomic analysis of the zebra finch degradome provides new insights into evolution of proteases in birds and mammals
}

\author{
Víctor Quesada1', Gloria Velasco1, Xose S Puente1, Wesley C Warren² and Carlos López-Otín*1
}

\begin{abstract}
Background: The degradome -the complete repertoire of proteases in an organism- is involved in multiple key biological and pathological processes. Previous studies in several organisms have yielded sets of curated protease sequences which may be used to characterize the degradome in a novel genome by similarity. Differences between degradomes can then be related to physiological traits of the species under study. Therefore, the sequencing of the zebra finch genome allows the comparison between the degradomes of mammals and birds and may help to understand the biological peculiarities of the zebra finch.

Results: A set of curated protease sequences from humans and chicken was used to predict the sequences of 460 protease and protease-like genes in the zebra finch genome. This analysis revealed important differences in the evolution of mammalian and bird degradomes, including genomic expansions and deletions of caspases, cytotoxic proteases, kallikreins, matrix metalloproteases, and trypsin-like proteases. Furthermore, we found several zebra finchspecific features, such as duplications in CASP3 and BACE, and a large genomic expansion of acrosin.

Conclusions: We have compared the degradomes of zebra finch, chicken and several mammalian species, with the finding of multiple differences which illustrate the evolution of the protease complement of these organisms. Detailed analysis of these changes in zebra finch proteases has shown that they are mainly related to immunological, developmental, reproductive and neural functions.
\end{abstract}

\section{Background}

The degradome is defined as the set of proteases present in an organism [1]. The coining of this term reflects the enormous biological and pathological relevance of proteolysis that pervades virtually every aspect of life, including development, apoptosis, host defense, nutrition, reproduction and central nervous system biology [2]. From a genomic perspective, the degradome provides a relatively simple representative subset of the coding genome of a species. Thus, the human degradome contains about 570 proteases, and can be studied with semiautomated methods. On the other hand, and despite proteases share a common biochemical function, their catalytic domains exhibit high sequence diversity. This

\footnotetext{
*Correspondence: clo@uniovi.es

${ }^{1}$ Departamento de Bioquímica y Biología Molecular, Facultad de Medicina, Instituto Universitario de Oncología, Universidad de Oviedo, 33006-Oviedo, Spain

Full list of author information is available at the end of the article
}

diversity is further increased by the frequent attachment of auxiliary, non-proteolytic domains to the catalytic moieties [3]. It is also remarkable that while some of the protease genes are clustered, most of them are randomly distributed throughout the annotated genomes [4-7]. Hence, the degradome forms a representative subset of the coding genome of a species, both in terms of sequence and genomic organization.

Furthermore, since the role of multiple proteases in biological processes is well documented, the comparative study of degradomes may improve our understanding of these processes in different organisms. The zebra finch (Taeniopygia guttata) is a bird which has been extensively used as a model organism for neurological [8], reproductive [9], and immune [10] studies. Therefore, the characterization of the zebra finch degradome may provide valuable information on the role of proteases in key biological processes. 
In this work, we report the analysis of the complete set of protease and protease-like genes in the zebra finch genome and its comparison to the chicken and human degradomes. Where appropriate, other mammalian degradomes have also been considered to expand the scope of this protease-based comparative genomic analysis.

\section{Results and Discussion}

As expected, we have found that the zebra finch degradome is similar to the chicken degradome. According to our preliminary prediction, the zebra finch and chicken degradomes contain about 460 proteases. Reciprocal best hit analysis of these results with the Ensembl predicted protein complement of chicken showed that 380 zebra finch proteases have a reciprocal best hit orthologue in the chicken degradome. In contrast, 80 predicted zebra finch proteases have no clear orthologue in chicken. Most of these proteases belong to large complex families, in which orthology assignment is difficult to establish. It must also be noted that gene gains and losses may be confused with lack of genomic data and assembly artefacts. However, some of these zebra finch specific proteases seem to have clearly arisen from species-specific duplications.

Comparison of these degradomes with the human degradome has yielded further information about the evolution of proteases and has led to hypothesis about their putative roles in zebra finch physiology. Thus, most of the major differences characteristic of the zebra finch and chicken degradomes compared to mammalian degradomes affect proteases involved in a few key biological processes, including apoptosis, host defense, teeth formation, reproduction, and neural development.

\section{Apoptosis}

The detailed comparative analysis of proteases involved in apoptosis has revealed a series of zebra finch and avian characteristic features. Thus, group I caspases, involved in the processing of inflammatory cytokines, is composed of CASP1, $-4,-5$, and -12 in humans [11] and only one (CASP1) in chicken. We have not found any sequence corresponding to group I caspases in the current assembly of zebra finch nor in zebra finch ChrUn assembly or sequence traces, nor in EST databases. However, the genomic contig in which this sequence should be located is rich in unsequenced stretches. Since this protease is expected to play a very important role in apoptosis induced by bacterial infections, it seems likely that the gene encoding caspase- 1 exists in an unsequenced stretch of the zebra finch genome. Nevertheless, further experimental validation will be necessary to clarify this important question.
On the other hand, the degradomes of zebra finch and chicken contain several caspases which are not present in humans [12] (Figure 1). Thus, CASP18 is present in both birds. The phylogenetic analysis of this gene is consistent with the proposed evolutionary history of this gene, which is present in opossum and absent in placental mammals [12]. Another gene absent in mammals is CASP17, which can be found in chicken. Surprisingly, we have not found any orthologue of CASP17 in the zebra finch genome. In contrast, there is evidence for a tandem duplication of CASP3 in the zebra finch genome, but not in the genomes of chicken or human. Taken together, these results suggest that the mechanisms leading to caspase-dependent apoptosis in birds might depend on more proteases than in mammals. In fact, the evolution of caspases in mammals includes complex events, like the pseudogenization of CASP12 in most of the human population but not in other hominoids [13]. These changes may influence processes such as immune system maturation and inflammatory response. In this regard, it is note-

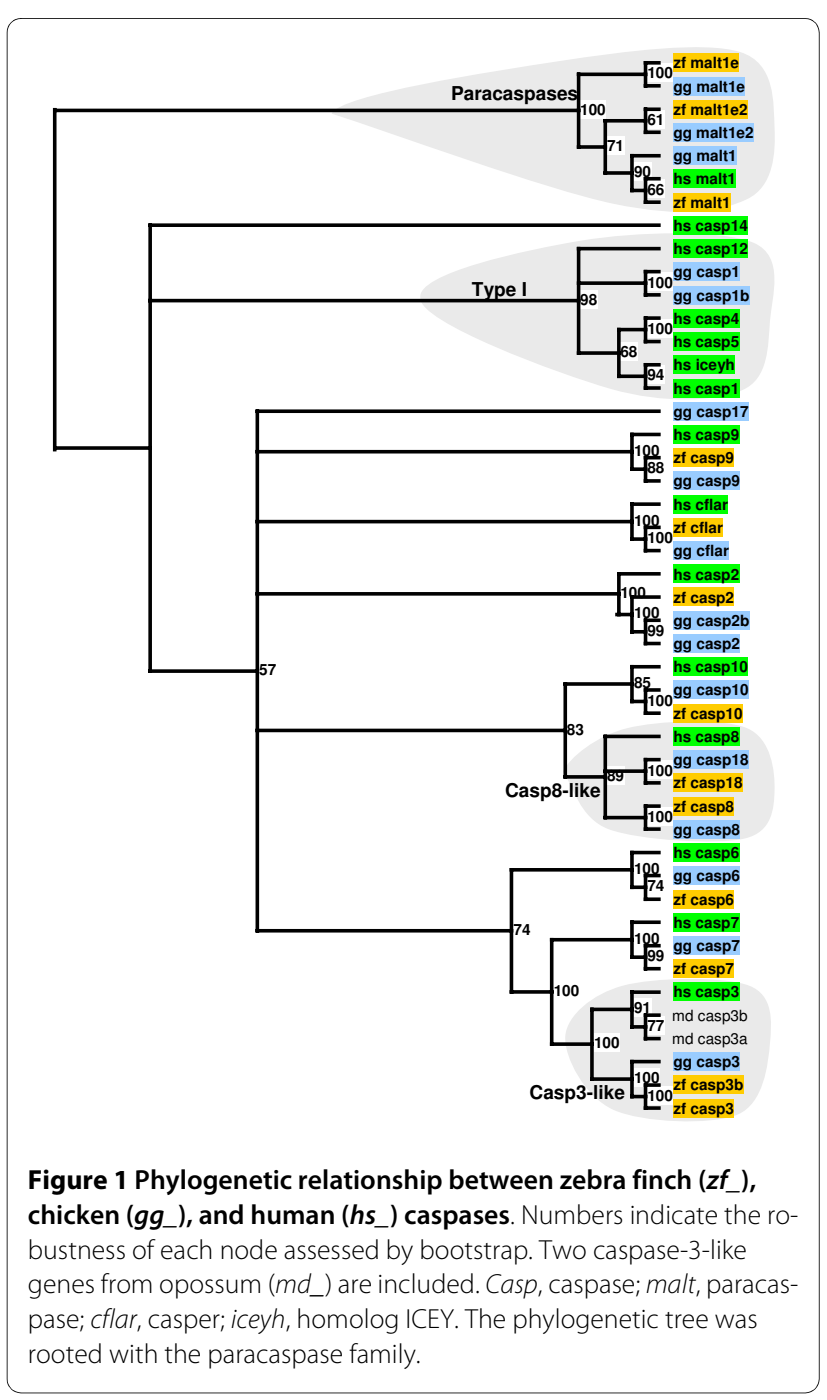


worthy that recent data have indicated that blocking caspase-mediated apoptosis reduces neurogenesis in the song nucleus of a bird [14].

\section{Host defense}

Proteases play important roles in the immune defense against pathogens by acting as cytotoxic agents or by contributing to processes of activation and proliferation of immune cells. The pressure of pathogens on the evolution of the immune system has likely led to marked differences in these proteases between birds and mammals.

Immune cytotoxic proteases are serine proteases stored in the granules of neutrophils, mast cells, and natural killer lymphocytes and released upon activation. Once released, these proteases promote apoptosis of infected cells [15]. In humans, the genes encoding cytotoxic proteases are clustered in three genomic loci. The first cluster contains the genes encoding granzymes A (GZMA) and $\mathrm{K}(G Z M K)$. As shown in Figure 2, GZMK is absent in the genomes of zebra finch and chicken, whereas GZMA is conserved in both birds. The second human cluster contains neutrophil elastase (ELA2), complement factor $\mathrm{D}(D F)$, azurocidin (AZU1), and proteinase 3 (PRTN3).



Figure 2 Phylogenetic relationship between zebra finch (zf_), chicken (gg_), and human ( $h s_{-}$) proteases in granzyme clusters. Numbers indicate the robustness of each node assessed by bootstrap. Azu1, azurocidin-1; df2, complement factor D; ela2, neutrophil elastase; prtn3, proteinase 3; gzm, granzyme; ela, elastase; cmal, chymase. Human azurocidin is included as an outgroup.
This cluster seems to be lacking in both zebra finch and chicken (Figure 2). Finally, the third human cluster contains granzyme $\mathrm{B}(G Z M B)$, granzyme $\mathrm{H}(G Z M H)$, cathepsin G (CTSG), and chymase (CMA1). The genomes of both zebra finch and chicken contain a single protease gene related to all four human proteases, which we have named GZMZ. Notably, this protease has been duplicated in the zebra finch. The resulting novel zebra finchspecific granzyme (GZMZL) is classified as a non-peptidase homolog, lacking proteolytic capabilities, since its sequence features two substitutions at key catalytic residues. It should be noted that the most abundant granzymes in humans are A and B, which cause caspaseindependent and caspase-dependent apoptosis, respectively. Therefore, this analysis predicts that avian granzyme $\mathrm{A}$ and granzyme $\mathrm{Z}$ may play complementary roles in the cytotoxic immune response. If expressed, granzyme Z-like might modulate the activity of granzyme $\mathrm{Z}$ by sequestering its substrates or inhibitors. Furthermore, it has been suggested that some of these granzymes absent in birds induce cell death by mitochondrial or autophagy-related pathways [16].

On the other hand, human cysteine protease paracaspase (MALT1) has been shown to modulate T-cell activation [17]. Our analysis has uncovered the zebra finch and chicken orthologues of MALT1, along with two additional paracaspase-like genes in zebra finch and chicken, which are not present in human. The phylogenetic analysis of caspases suggests that the common ancestor to mammals and birds had three copies of MALT1, two of which were lost in mammals (Figure 1). This result is supported by the finding of three MALT1-like genes in Tetraodon nigroviridis (CAG08114.1, CAG07960.1, and CAG13116.1).

Taken together, these results suggest that the mammalian granzyme clusters constitute an evolutionary response to special immune challenges, and that the cytotoxic immune response in humans proceeds through more diverse cellular pathways than the corresponding response in birds. In contrast, immune cell activation dependent on paracaspases, might involve more proteases in birds than in mammals.

\section{Teeth formation}

Absence of teeth is a specific feature of birds and adult monotremes. The analysis of avian degradomes shows that both zebra finch and chicken lack two protease genes involved in teeth formation, namely the genes encoding enamelysin (MMP2O) and kallikrein-4 (KLK4) [18-20]. While KLK4 is absent in both bird genomes, along with the rest of the kallikrein family of serine proteases, a pseudogene resembling $M M P 20$ can be found in a syntenic locus in the chicken genome, but not in the zebra finch genome. Both proteases cleave several enamel pro- 
teins necessary for enamel formation in all dentate vertebrates.

Likewise, orthologues of human enamel matrix protein genes (AMBN, AMELX, and ENAM) are absent from avian genomes. In contrast, other non-dentate vertebrates, like platypus, contain orthologues of these genes. This may reflect the fact that, unlike birds, young monotremes display rudimentary teeth. Other genes involved in teeth and bone development are also absent in chicken and zebra finch genomes, including the genes encoding matrix extracellular phosphoprotein $(M E P E)$ and dentine-sialophosphoprotein $(D S P P)$. Therefore, teeth loss in birds seems to have proceeded through multiple gene losses, including proteases and protease substrates.

\section{Reproduction}

One of the most dissimilar processes between birds and mammals is reproduction. Consistent with this, we have found multiple differences in protease genes involved in fecundation and embryo hatching. Thus, no orthologues of testin serine proteases were found in chicken or zebra finch. In mammals, testins have been linked to spermatogenesis based on localization studies [21]. Testin genes have followed diverse evolutionary patterns, with pseudogenization events in some primates and rodents [4-6]. This suggests that testins might be related to reproductive fitness or even to speciation specifically in mammals. Likewise, several members of the ADAM family of metalloproteases involved in fertilization in mammals are lacking in the genomes of both birds. These include ADAMs 1-7 and ADAM30. In contrast, other members of this family not involved in reproductive processes are conserved. Notably, a family of two pregnancy-associated plasma metalloproteases, pappalysin-1 and -2 (PAPPA1 and PAPPA2), seem to be perfectly conserved in birds. Pappalysins are known to cleave IGF-binding proteins (IGFBPs), and overexpression of PAPPA2 is related to severe preeclampsia in humans [22]. This result suggests that IGFBP proteases may play a conserved role in pregnancy both in birds and mammals.

On the other hand, acrosin, a serine protease located in the sperm acrosome and involved in the lysis of the zona pellucida to facilitate sperm penetration in the ovum, is conserved in birds and mammals [23]. Strikingly, while the genomes of humans and chickens contain a single acrosin gene $(A C R)$, the zebra finch genome contains 7 non-clustered $A C R$-like genes. These include a non-peptidase homolog, named $A C R 1$, featuring mutations in all three catalytic residues. Since no orthologues of these novel genes have been found in other organisms, $A C R$ like genes are likely to be due to zebra finch-specific genomic expansions. As shown in Figure 3, some of these zebra finch-specific acrosin-like genes, especially ACR5, seem to have undergone non-neutral evolution, likely

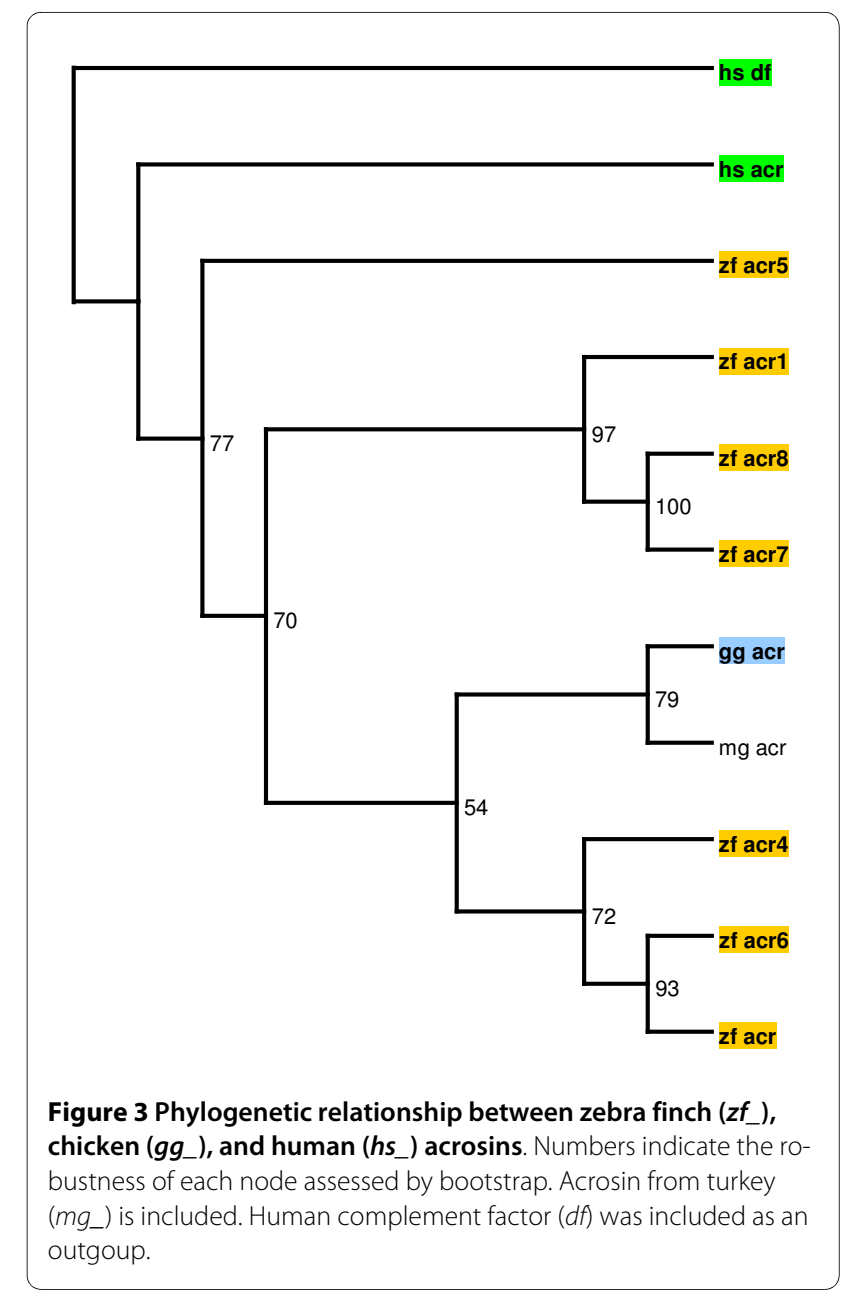

reflecting reproductive pressures. However, we cannot rule out the possibility of an ancestral genomic expansion of $A C R$ followed by loss of the novel genes in several species. The substrates of acrosin are called zona pellucida proteins or ZPs. The human genome encodes four ZP proteins, whereas the chicken genome encodes six $\mathrm{ZP}$ family members and the zebra finch genome seven ZPs, due to the specific duplication of ZPAX [24].

Consistent with the important differences in reproduction between birds and mammals after fertilization, proteases involved in implantation in mammals and hatching are not conserved. Thus, we have found no evidence of zebra finch or chicken proteases related to murine implantation serine proteases (ISPS), which have been shown to participate in embryo implantation and may be involved in embryo hatching [25]. Furthermore, the gene encoding mammalian ovastacin, a metalloprotease which may be involved in embryo hatching [26], is absent in zebra finch and chicken. In contrast, we have found two zebra finch proteases related to fish choryolytic enzymes, which may fulfill this role in embryo hatching. Finally, our analysis has revealed features specific of eutherian organ- 
isms. Thus, the alpha-aspartyl dipeptidase gene (PEPE), conserved in bacteria, vertebrates, and invertebrates, is present both in zebra finch and chicken, but not in eutherians. Likewise, the gene encoding the aspartyl protease known as nothepsin (NOTS) is present in both birds as well as in fish, reptilia and platypus but has been pseudogenized in metatherians and eutherians. Interestingly, both PEPE and NOTS are highly expressed in reproductive organs of different species. This suggests that the inactivation of these genes, with the concomitant expansion of other protease families, may have played a role in the striking reproductive differences between oviparous and viviparous species.

Taken together, these data show that the profound differences in the reproductive function between birds and mammals are related to multiple gene gain and loss events. Our results suggest that the evolutionary pressure on the reproductive function has driven the expansion of the acrosin family of serine proteases in zebra finch, but not in chicken or mammals. This abrupt change in genes involved in reproduction could potentially lead to reproductive barriers and thus play an important role in speciation.

\section{Neural development}

The zebra finch is an interesting model of neural development. As noted above, the zebra finch genome features a zebra finch-specific CASP3 duplication. This event may have important consequences in neural development regardless of the role of this protease in apoptosis. In fact, recent studies have shown that zebra finch $C A S P 3$ plays a dynamic role in song-response habituation, and therefore is involved in learning and memory [27]. It is important to notice that this result requires experimental validation, since tandem duplication can be mimicked by artifacts in the genomic assembly. Notably, we have found embryo EST sequences corresponding to both CASP 3 copies. On the other hand, an independent CASP3 duplication has been shown in opossum [12].

Additionally, we have found a zebra finch-specific tandem duplication of the gene encoding the aspartyl protease $\beta$-secretase 1 (BACE). Strikingly, both CASP3 and $B A C E$ have been shown to play a role in $\alpha \beta$ peptide accumulation in Alzheimer disease [28]. Since this role is related to $\beta$-secretase, it is tempting to speculate that $\beta$ secretase activity and regulation in birds may be influenced by these novel copies of CASP 3 and BACE.

Finally, our analysis suggests that the gene encoding the serine protease neurotrypsin (PRSS12) was duplicated in an ancestor of birds and mammals, and then one copy was lost in the mammalian lineage (data not shown). Neurotrypsin has been linked to neural development in multiple organisms. Thus, a 4 bp deletion in human PRSS12 mRNA is believed to cause mental retardation
[29]. Likewise, a Drosophila melanogaster strain lacking the orthologue of neurotrypsin has been shown to suffer a long-term memory formation defect [30].

Collectively, these results show several putative duplication events in protease genes involved in neural development. This suggests that gene gain by genomic duplication may underlie some of the differences in neural development between zebra finch and chicken.

\section{Differences in other proteases}

Additional features of the zebra finch degradome may provide clues about the evolution of the zebra finch genome compared to other birds and mammals. Thus, the human genome encodes 24 matrix metalloprotease $(M M P)$ genes, involved in multiple biological processes, including development and tissue remodeling [31]. Inspection of the chicken and zebra finch genomes shows that the number of MMPs is much lower, with 16 members each, due to the lack of $M M P-7,-8,-19,-20,-21$, $23 B,-25$, and -26 . These dissimilar MMP gene sets might underlie some of the differences in bone and cartilage biology or in other tissue-remodelling events between birds and mammals.

Furthermore, while most of the genes in the ADAMTS metalloprotease family are perfectly conserved between zebra finch, chicken, and human, ADAMTS13 seems to have been specifically duplicated in zebra finch. It is remarkable that this gene has been related to a human disease called thrombotic thrombocytopenic purpura [32]. This disease causes hemolytic anemia with fragmentation of erythrocytes, thrombocytopenia, diffuse and nonfocal neurologic findings, and decreased renal function. Notably, two members of this family present in humans are lacking in birds. These are ADAMTS16, expressed in pre-ovulatory ovarian follicules [33] and linked to inherited hypertension [34], and ADAMTS4, which encodes a protease involved in aggrecan degradation and may play a role in the development of osteoarthritis [35]. This suggests that, in birds, other aggrecanases, like ADAMTS-5, fulfill the tasks that ADAMTS-4 performs in mammals.

Finally, the differences in the diets of birds and mammals seem to have prompted the remodelling of the pepsinogen system. Thus, while the human genome contains three pepsinogen A ( $P G A)$ genes in tandem, birds possess two $P G A$ genes duplicated independently. Furthermore, while the chicken genome contains an ortholog of human pepsinogen $C(P G C)$, the zebra finch genome seems to be lacking this gene.

We have also found evidence for changes in multiple protease genes which are currently being validated (Table 1). Our ongoing studies on these genes may extend the list of differences in the degradomes of zebra finch, chicken, and humans. 
Table 1: Comparison of the zebra finch, chicken, human, and mouse degradomes

\begin{tabular}{|c|c|c|c|c|}
\hline Gene & Zebra finch & Chicken & Human & Mouse \\
\hline \multicolumn{5}{|c|}{ Apoptosis } \\
\hline Caspase- $1,-4,-5,-12$ & Not found & Only caspase-1 & All & All \\
\hline Caspase-17 & Not found & Present & Absent & Absent \\
\hline Caspase-18 & Present & Present & Absent & Absent \\
\hline \multicolumn{5}{|c|}{ Host defense } \\
\hline Granzyme K & Absent & Absent & Present & Present \\
\hline Neutrophil elastase & Absent & Absent & Present & Present \\
\hline Complement factor D & Absent & Absent & Present & Present \\
\hline Azurocidin & Absent & Absent & Present & Absent \\
\hline Proteinase 3 & Absent & Absent & Present & Present \\
\hline $\begin{array}{l}\text { Granzymes B and } \mathrm{H} \text {, } \\
\text { cathepsin } \mathrm{G} \text {, chymase }\end{array}$ & Granzyme $Z$ and $Z$-like & Granzyme Z & All & All \\
\hline PRSS33 & Absent & Absent & Present & Present \\
\hline Tryptases & Absent & Absent & Present & Present \\
\hline Haptoglobins & Absent & Absent & Two & One \\
\hline Cathepsin F & Absent & Absent & Present & Present \\
\hline Cathepsin W & Absent & Absent & Present & Present \\
\hline PRSS16 & Absent & Absent & Present & Present \\
\hline Paracaspase & Triplicated & Triplicated & Present & Present \\
\hline Legumain-2 & Absent & Absent & Present & Present \\
\hline \multicolumn{5}{|c|}{ Tissue development } \\
\hline Enamelysin & Absent & Absent & Present & Present \\
\hline Kallikrein-4 & Absent & Absent & Present & Present \\
\hline $\begin{array}{l}\text { MMP-7, }-8,-19,-21,- \\
23 B,-25\end{array}$ & Absent & Absent & Present & Present \\
\hline MMP-26 & Absent & Absent & Present & Absent \\
\hline ADAMTS-4 & Absent & Absent & Present & Present \\
\hline \multicolumn{5}{|c|}{ Reproduction } \\
\hline $\begin{array}{l}\text { Alpha-aspartyl } \\
\text { dipeptidase }\end{array}$ & Present & Present & Absent & Absent \\
\hline Nothepsin & Present & Present & Absent & Absent \\
\hline ADAMTS-16 & Absent & Absent & Present & Present \\
\hline Testins & Absent & Absent & Present & Present \\
\hline ADAM3B, $-4,-4 B,-5,-6$ & Absent & Absent & Pseudogenes & Present \\
\hline ADAM7 & Absent & Absent & Present & Present \\
\hline ADAM30 & Absent & Absent & Present & Present \\
\hline Acrosin & Expanded & Present & Present & Present \\
\hline $\begin{array}{l}\text { Prolactin-induced } \\
\text { protein }\end{array}$ & Absent & Absent & Present & Present \\
\hline Ovastacin & Absent & Absent & Present & Present \\
\hline ISP1 & Absent & Absent & Absent & Present \\
\hline ISP2 & Absent & Absent & Pseudogene & Present \\
\hline Choryolytic enzymes & Present & Present & Absent & Absent \\
\hline
\end{tabular}


Table 1: Comparison of the zebra finch, chicken, human, and mouse degradomes (Continued)

\begin{tabular}{|c|c|c|c|c|}
\hline \multicolumn{5}{|c|}{ Neural development } \\
\hline Caspase-3 & Duplicated & Present & Present & Present \\
\hline Neurotrypsin & Duplicated & Duplicated & Present & Present \\
\hline Bace & Duplicated & Present & Present & Present \\
\hline Presenilin homolog-2 & Absent & Absent & Present & Present \\
\hline $\begin{array}{l}\text { Transmembraneserine } \\
\text { protease } 5\end{array}$ & Absent & Present & Present & Present \\
\hline Brain serine protease- 2 & Absent & Absent & Present & Present \\
\hline \multicolumn{5}{|c|}{ Other } \\
\hline Pepsinogen A & Duplicated & Duplicated & Triplicated & Present \\
\hline Pepsinogen C & Not found & Present & Present & Present \\
\hline ADAMTS-13 & Duplicated & Present & Present & Present \\
\hline $\begin{array}{l}\text { Tubulointerstitial } \\
\text { nephritis antigen-like } 1\end{array}$ & Absent & Absent & Present & Present \\
\hline $\begin{array}{l}\text { Desert hedgehog } \\
\text { protein }\end{array}$ & Absent & Absent & Present & Present \\
\hline Sentrin-3 & Absent & Absent & Present & Present \\
\hline Autophagin-4 & Absent & Absent & Present & Present \\
\hline NAALADASE like 1 & Absent & Absent & Present & Present \\
\hline Transferrin receptor 2 & Absent & Absent & Present & Present \\
\hline Dipeptidyl-peptidase 3 & Absent & Absent & Present & Present \\
\hline $\begin{array}{l}\text { Vitellogenic-like } \\
\text { carboxypeptidase }\end{array}$ & Absent & Absent & Present & Present \\
\hline $\begin{array}{l}\text { ClpP caseinolytic } \\
\text { peptidase }\end{array}$ & Absent & Absent & Present & Present \\
\hline $\begin{array}{l}\text { Abhydrolase domain } \\
\text { containing } 4\end{array}$ & Absent & Absent & Present & Present \\
\hline Polyserases & One & One & Three & Three \\
\hline Kallikreins & Absent & Absent & Present & Present \\
\hline $\begin{array}{l}\text { Ubiquitin-specific } \\
\text { protease-11 }\end{array}$ & Absent & Absent & Present & Present \\
\hline
\end{tabular}

\section{Conclusions}

In summary, the analysis of the zebra finch degradome and its comparison with those of other birds and mammals may prove useful in the identification of molecular mechanisms which underlie physiological differences between these organisms. Thus, we have identified changes in protease-coding genes such as caspases, granzymes, acrosins, metalloproteases, and pepsinogens, which might underlie differences in apoptosis, immune system, bone and teeth development, and reproduction. This approach has also allowed us to generate hypothesis about the role of several proteolytic systems in the striking differences in neural development between zebra finch and other birds. In this regard, we have found zebra finch-specific duplications in protease genes involved in neural development, namely $C A S P 3$ and $B A C E$. We expect that these results may contribute to our better understanding of avian biology and zebra finch characteristic traits.

\section{Methods}

Identification and annotation of zebra finch proteases

To annotate the set of zebra finch proteases, we downloaded the zebra finch genomic sequence deposited in the Genome Center at Washington University, in the context of the Zebra Finch Sequencing and Analysis Consortium (Zebra Finch Sequencing and Analysis Consortium: The genome sequence of the vocal learning zebra finch, submitted). Protease sequences were found and curated with the BATI algorithm (Blast, Annotate, Tune, Iterate), using four in-house Perl scripts: Tbex, BlastSniffer, GeneTuner, and BGmix http://degradome.uniovi.es/downloads. We started with a previously assembled set including curated human [6] and chicken http://www.ensembl.org protease 
sequences. Each protein sequence in this starting set was compared to the genomic sequence of zebra finch using the TBLASTN program of the BLAST suite [36] with Tbex. Putative orthologues of the starting genes were located with BlastSniffer and curated with GeneTuner. To minimize the number of missed protease genes, a composite file with all of the TBLASTN hits sorted by chromosomal location was also generated with BGmix and inspected. Prediction of chicken and human orthologues was performed by reciprocal best hit analysis. Information on the degradomes of other mammalian species was retrieved from the Degradome database http://degradome.uniovi.es.

\section{Phylogenetic analysis}

In those cases where orthology could not be established by reciprocal best hit analysis, phylogenetic studies were conducted. Protein sequences were aligned with ClustalX [37] and manually edited with Genedoc http:// www.nrbsc.org/gfx/genedoc/index.html. Then, alignments were bootstrapped 100 times with Seqboot and most parsimonious trees were generated with Protpars, both from the Phylip package http://evolution.genetics.washington.edu/phylip.html. Trees were displayed with TreeView [37]. Only nodes present in more than 50 bootstrapped trees were displayed.

\section{Authors' contributions}

VQ participated in the study design, performed the annotation process and contributed to write the manuscript; GV participated in the validation of the results; XSP participated in the curation of the initial sequence set; WW participated in the design of the study and CLO participated in the design and coordination of the work and helped to draft the manuscript. All authors read and approved the final manuscript.

\section{Acknowledgements}

This work was supported by grants from the European Union (FP7-Microenvimet), Ministerio de Ciencia e Innovación-Spain and Fundación M. Botín. The Instituto Universitario de Oncología is supported by Obra Social Cajastur and Acción Transversal del Cáncer-RTICC.

\section{Author Details}

'Departamento de Bioquímica y Biología Molecular, Facultad de Medicina, Instituto Universitario de Oncología, Universidad de Oviedo, 33006-Oviedo, Spain and ${ }^{2}$ Genome Sequencing Center, Washington University School of Medicine, St Louis, Missouri, USA

Received: 16 November 2009 Accepted: 1 April 2010 Published: 1 April 2010

\section{References}

1. Quesada V, Ordonez GR, Sanchez LM, Puente XS, Lopez-Otin C: The Degradome database: mammalian proteases and diseases of proteolysis. Nucleic Acids Res 2009, 37:D239-243.

2. Lopez-Otin C, Bond JS: Proteases: multifunctional enzymes in life and disease. J Biol Chem 2008, 283:30433-30437.

3. Lopez-Otin C, Overall CM: Protease degradomics: a new challenge for proteomics. Nat Rev Mol Cell Biol 2002, 3:509-519.

4. Puente XS, Gutierrez-Fernandez A, Ordonez GR, Hillier LW, Lopez-Otin C: Comparative genomic analysis of human and chimpanzee proteases. Genomics 2005, 86:638-647.

5. Puente XS, Lopez-Otin C: A genomic analysis of rat proteases and protease inhibitors. Genome Res 2004, 14:609-622.
6. Puente XS, Sanchez LM, Overall CM, Lopez-Otin C: Human and mouse proteases: a comparative genomic approach. Nat Rev Genet 2003, 4:544-558.

7. Ordonez GR, Hillier LW, Warren WC, Grutzner F, Lopez-Otin C, Puente XS: Loss of genes implicated in gastric function during platypus evolution. Genome Biol 2008, 9:R81

8. Nottebohm F: The road we travelled: discovery, choreography, and significance of brain replaceable neurons. Ann N Y Acad Sci 2004, 1016:628-658

9. Williams TD, Vezina F, Speakman JR: Individually variable energy management during egg production is repeatable across breeding attempts. J Exp Biol 2009, 212:1101-1105.

10. Love OP, Salvante KG, Dale J, Williams TD: Sex-specific variability in the immune system across life-history stages. Am Nat 2008, 172:E99-112.

11. Kersse K, Vanden T Berghe, Lamkanfi M, Vandenabeele P: A phylogenetic and functional overview of inflammatory caspases and caspase-1related CARD-only proteins. Biochem Soc Trans 2007, 35:1508-1511

12. Eckhart L, Ballaun C, Hermann M, VandeBerg JL, Sipos W, Uthman A, Fischer $\mathrm{H}$, Tschachler E: Identification of novel mammalian caspases reveals an important role of gene loss in shaping the human caspase repertoire. Mol Biol Evol 2008, 25:831-841.

13. Fischer H, Koenig U, Eckhart L, Tschachler E: Human caspase 12 has acquired deleterious mutations. Biochem Biophys Res Commun 2002, 293:722-726

14. Thompson CK, Brenowitz EA: Neurogenesis in an adult avian song nucleus is reduced by decreasing caspase-mediated apoptosis. Neurosci 2009, 29:4586-4591.

15. Regner M, Pavlinovic L, Koskinen A, Young N, Trapani JA, Mullbacher A Cutting edge: rapid and efficient in vivo cytotoxicity by cytotoxic $T$ cells is independent of granzymes A and B. J Immunol 2009, 183:37-40.

16. Chowdhury D, Lieberman J: Death by a thousand cuts: granzyme pathways of programmed cell death. Annu Rev Immunol 2008, 26:389-420.

17. Thome M: Multifunctional roles for MALT1 in T-cell activation. Nat Rev Immunol 2008, 8:495-500.

18. Hart PS, Hart TC, Michalec MD, Ryu OH, Simmons D, Hong S, Wright JT: Mutation in kallikrein 4 causes autosomal recessive hypomaturation amelogenesis imperfecta. J Med Genet 2004, 41:545-549.

19. Kim JW, Simmer JP, Hart TC, Hart PS, Ramaswami MD, Bartlett JD, Hu JC: MMP-20 mutation in autosomal recessive pigmented hypomaturation amelogenesis imperfecta. J Med Genet 2005, 42:271-275.

20. Llano E, Pendas AM, Knauper V, Sorsa T, Salo T, Salido E, Murphy G, Simmer JP, Bartlett JD, Lopez-Otin C: Identification and structural and functional characterization of human enamelysin (MMP-20). Biochemistry 1997, 36:15101-15108.

21. Takano N, Kimura A, Takahashi T: Two distinct localization patterns of testis-specific serine protease 1 (TESSP1) in the seminiferous tubules of the mouse testis. Zoolog Sci 2009, 26:294-300.

22. Winn VD, Gormley M, Paquet AC, Kjaer-Sorensen K, Kramer A, Rumer KK, Haimov-Kochman R, Yeh RF, Overgaard MT, Varki A, Oxvig C, Fisher SJ: Severe preeclampsia-related changes in gene expression at the maternal-fetal interface include sialic acid-binding immunoglobulinlike lectin-6 and pappalysin-2. Endocrinology 2009, 150:452-462.

23. Berlin S, Qu L, Ellegren H: Adaptive evolution of gamete-recognition proteins in birds. $J \mathrm{Mol}$ Evol 2008, 67:488-496.

24. Goudet G, Mugnier S, Callebaut I, Monget P: Phylogenetic analysis and identification of pseudogenes reveal a progressive loss of zona pellucida genes during evolution of vertebrates. Biol Reprod 2008, 78:796-806

25. Sharma N, Liu S, Tang L, Irwin J, Meng G, Rancourt DE: Implantation Serine Proteinases heterodimerize and are critical in hatching and implantation. BMC Dev Biol 2006, 6:61.

26. Quesada V, Sanchez LM, Alvarez J, Lopez-Otin C: Identification and characterization of human and mouse ovastacin: a novel metalloproteinase similar to hatching enzymes from arthropods, birds, amphibians, and fish. J Biol Chem 2004, 279:26627-26634.

27. Huesmann GR, Clayton DF: Dynamic role of postsynaptic caspase-3 and BIRC4 in zebra finch song-response habituation. Neuron 2006, 52:1061-1072

28. Tesco G, Koh YH, Kang EL, Cameron AN, Das S, Sena-Esteves M, Hiltunen M, Yang SH, Zhong Z, Shen Y, Simpkins JW, Tanzi RE: Depletion of GGA3 
stabilizes BACE and enhances beta-secretase activity. Neuron 2007, 54:721-737.

29. Molinari F, Rio M, Meskenaite V, Encha-Razavi F, Auge J, Bacq D, Briault S, Vekemans M, Munnich A, Attie-Bitach T, Sonderegger P, Colleaux L: Truncating neurotrypsin mutation in autosomal recessive nonsyndromic mental retardation. Science 2002, 298:1779-1781.

30. Didelot G, Molinari F, Tchenio P, Comas D, Milhiet E, Munnich A, Colleaux $L$, Preat T: Tequila, a neurotrypsin ortholog, regulates long-term memory formation in Drosophila. Science 2006, 313:851-853.

31. Fanjul-Fernandez M, Folgueras AR, Cabrera S, Lopez-Otin C: Matrix metalloproteinases: Evolution, gene regulation and functional analysis in mouse models. Biochim Biophys Acta 2010, 1803:3-19.

32. Levy GG, Nichols WC, Lian EC, Foroud T, McClintick JN, McGee BM, Yang AY, Siemieniak DR, Stark KR, Gruppo R, Sarode R, Shurin SB, Chandrasekaran V, Stabler SP, Sabio H, Bouhassira EE, Upshaw JD Jr, Ginsburg D, Tsai HM: Mutations in a member of the ADAMTS gene family cause thrombotic thrombocytopenic purpura. Nature 2001, 413:488-494.

33. Gao S, De Geyter C, Kossowska K, Zhang H: FSH stimulates the expression of the ADAMTS-16 protease in mature human ovarian follicles. Mol Hum Reprod 2007, 13:465-471.

34. Joe B, Saad Y, Lee N, Frank B, Achinike O, Luu T, Gopalakrishnan K, Toland E, Farms P, Yerga-Woolwine S, Manickavasagam E, Rapp J, Garrett M, Coe D, Apte S, Rankinen T, Perusse L, Ehret G, Ganesh S, Cooper R, Connor A, Rice T, Weder A, Chakravarti A, Rao D, Bouchard C: Positional identification of variants of Adamts 16 linked to inherited hypertension. Hum Mol Genet 2009, 18:2825-2838.

35. Hardingham $\mathrm{T}$ : Extracellular matrix and pathogenic mechanisms in osteoarthritis. Curr Rheumatol Rep 2008, 10:30-36.

36. Gertz EM, Yu YK, Agarwala R, Schaffer AA, Altschul SF: Composition-based statistics and translated nucleotide searches: improving the TBLASTN module of BLAST. BMC Biol 2006, 4:41.

37. Thompson JD, Gibson TJ, Plewniak F, Jeanmougin F, Higgins DG: The CLUSTAL_X windows interface: flexible strategies for multiple sequence alignment aided by quality analysis tools. Nucleic Acids Res 1997, 25:4876-4882

doi: 10.1186/1471-2164-11-220

Cite this article as: Quesada et al., Comparative genomic analysis of the zebra finch degradome provides new insights into evolution of proteases in birds and mammals BMC Genomics 2010, 11:220

Submit your next manuscript to BioMed Centra and take full advantage of:

- Convenient online submission

- Thorough peer review

- No space constraints or color figure charges

- Immediate publication on acceptance

- Inclusion in PubMed, CAS, Scopus and Google Scholar

- Research which is freely available for redistribution

Submit your manuscript at www.biomedcentral.com/submit
C Biomed Central 